\title{
Adeno-associated virus: from defective virus to effective vector Manuel AFV Gonçalves*
}

Address: Gene Therapy Section, Department of Molecular Cell Biology, Leiden University Medical Center, Wassenaarseweg 72, 2333 AL Leiden, the Netherlands

Email: Manuel AFV Gonçalves* - m.goncalves@lumc.nl

* Corresponding author

Published: 06 May 2005

Virology Journal 2005, 2:43 doi:10.1 186/1743-422X-2-43

This article is available from: http://www.virologyj.com/content/2/l/43

(c) 2005 Gonçalves; licensee BioMed Central Ltd.

This is an Open Access article distributed under the terms of the Creative Commons Attribution License (http://creativecommons.org/licenses/by/2.0), which permits unrestricted use, distribution, and reproduction in any medium, provided the original work is properly cited.

\begin{abstract}
The initial discovery of adeno-associated virus (AAV) mixed with adenovirus particles was not a fortuitous one but rather an expression of AAV biology. Indeed, as it came to be known, in addition to the unavoidable host cell, AAV typically needs a so-called helper virus such as adenovirus to replicate. Since the AAV life cycle revolves around another unrelated virus it was dubbed a satellite virus. However, the structural simplicity plus the defective and non-pathogenic character of this satellite virus caused recombinant forms to acquire centre-stage prominence in the current constellation of vectors for human gene therapy. In the present review, issues related to the development of recombinant AAV (rAAV) vectors, from the general principle to production methods, tropism modifications and other emerging technologies are discussed. In addition, the accumulating knowledge regarding the mechanisms of $\mathrm{rAAV}$ genome transduction and persistence is reviewed. The topics on rAAV vectorology are supplemented with information on the parental virus biology with an emphasis on aspects that directly impact on vector design and performance such as genome replication, genetic structure, and host cell entry.
\end{abstract}

\section{Adeno-associated virus biology} Genome structure, DNA replication and virus assembly

The human adeno-associated virus (AAV) was discovered in 1965 as a contaminant of adenovirus (Ad) preparations [1]. AAV is one of the smallest viruses with a non-enveloped icosahedral capsid of approximately $22 \mathrm{~nm}$ (Fig. 1), the crystal structure of which has been recently determined to a 3-angstrom resolution [2]. Because a co-infecting helper virus is usually required for a productive infection to occur, AAV serotypes are ascribed to a separate genus in the Parvoviridae family designated Dependovirus. Despite the high seroprevalence of AAV in the human population (approximately $80 \%$ of humans are seropositive for AAV2) the virus has not been linked to any human illness. The AAV has a linear single-stranded DNA genome of approximately 4.7-kilobases (kb). The AAV2 DNA ter- mini consist of a 145 nucleotide-long inverted terminal repeat (ITR) that, due to the multipalindromic nature of its terminal 125 bases, can fold on itself via complementary Watson-Crick base pairing and form a characteristic T-shaped hairpin structure (Fig. 2) [3]. According to the AAV DNA replication model [4] this secondary structure provides a free 3' hydroxyl group for the initiation of viral DNA replication via a self-priming strand-displacement mechanism involving leading-strand synthesis and double-stranded replicative intermediates (Fig. 3). The virus does not encode a polymerase relying instead on cellular polymerase activities to replicate its DNA [5]. The ITRs flank the two viral genes rep (replication) and cap (capsid) encoding nonstructural and structural proteins, respectively. The rep gene, through the use of two promoters located at map positions 5 (p5) and 19 (p19), and an 

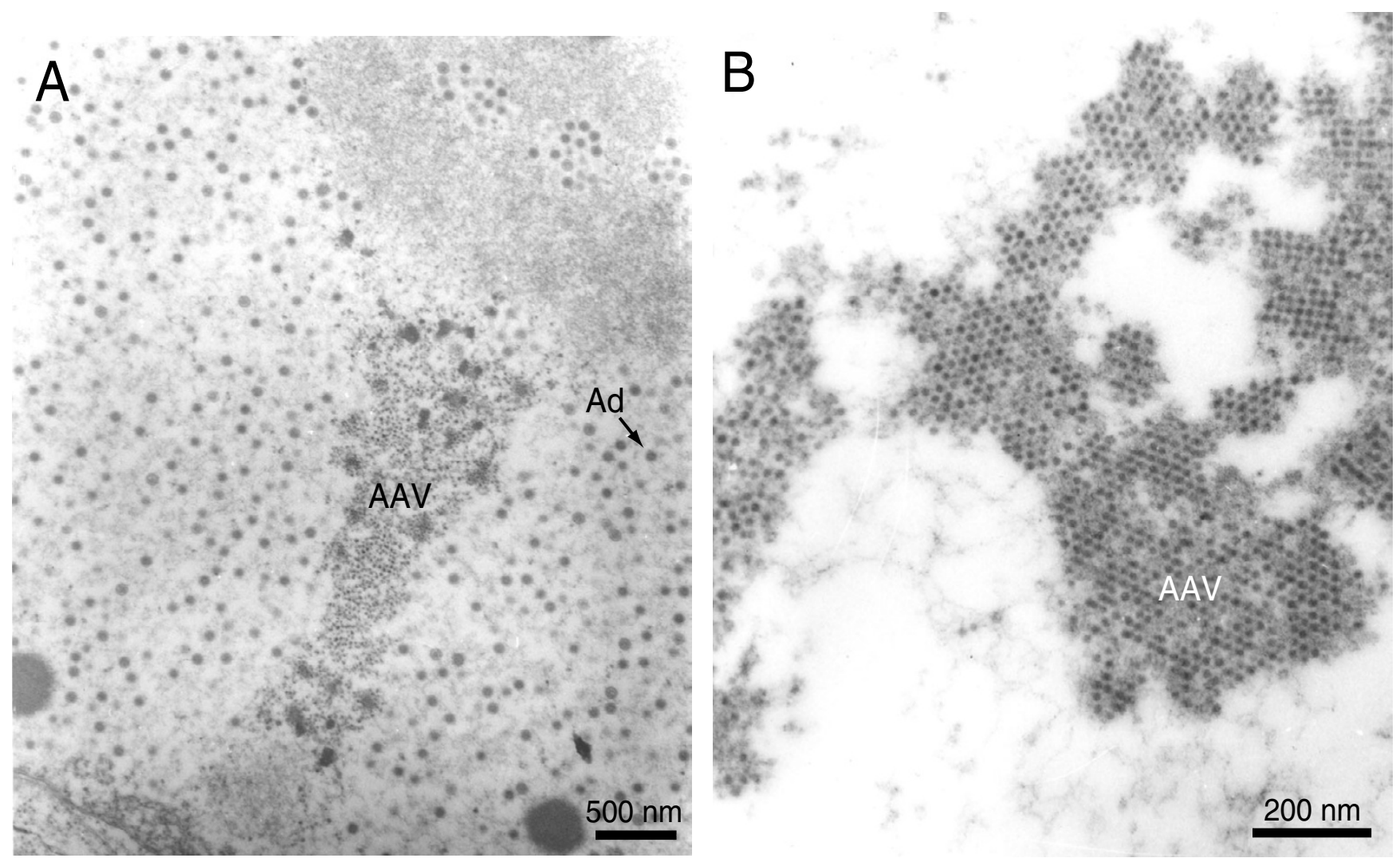

\section{Figure I}

Transmission electron microscopy of AAV2 and Ad5 particles in human cells. (A) AAV2 and Ad5 particles in the nucleus of a HeLa cell at 48 hours after co-infection. Magnification: $\times 15,000$. (B) AAV2 virions in a HeLa cell at 48 hours after co-infection with Ad5. Magnification: $\times$ 40,000.

internal splice donor and acceptor site, encode four regulatory proteins that are dubbed Rep78, Rep68, Rep52 and Rep40 on basis of their apparent molecular weights. The Rep78 and Rep68 proteins participate in the AAV DNA replication process via their interaction with Rep-binding element (RBE) and terminal resolution site (trs) sequences located within the ITRs (Fig. 2). In addition, in response to environmental cues such as presence or absence of a helper virus these proteins either positively or negatively regulate AAV gene expression, respectively [6]. The Rep52 and Rep40 proteins are involved in the generation and accumulation of single-stranded viral genomes from double-stranded replicative intermediates [7]. The resulting single-stranded genomes with plus and minus polarities are packaged with equal efficiency [8]. The economy displayed by AAV is staggering and derives not only from its overlapping genetic organization but also from the integration of various biochemical activities in each of its few gene products. For instance, Rep78 and Rep68 are site-specific DNA binding proteins, as well as strand- and site-specific endonucleases [9]. They also exhibit helicase and ATPase activities [10], which are shared by Rep52 [11] and by Rep40 [12].

The cap gene is transcribed from a single promoter at map position 40 (p40). Alternative splicing at two acceptor sites originates two transcripts. The larger transcript encodes virion protein 1 (VP1), the biggest capsid protein subunit. The shorter mRNA possesses a noncanonical start codon (ACG), which is utilized to generate VP2, and a downstream conventional initiation codon (AUG) directing the synthesis of VP3. The VP1, VP2 and VP3 proteins differ from each other at their $\mathrm{N}$ terminus and have apparent molecular masses of 87,72 and $62 \mathrm{kDa}$, respectively. Together they assemble into a near-spherical protein shell of 60 subunits with $\mathrm{T}=1$ icosahedral symmetry. At the 12 fivefold axes of symmetry lay narrow pores lately shown to be instrumental for virus infectivity and for genome packaging [13]. The molar ratio between VP1, VP2 and VP3 in AAV particles is 1:1:10. This stoichiometry 


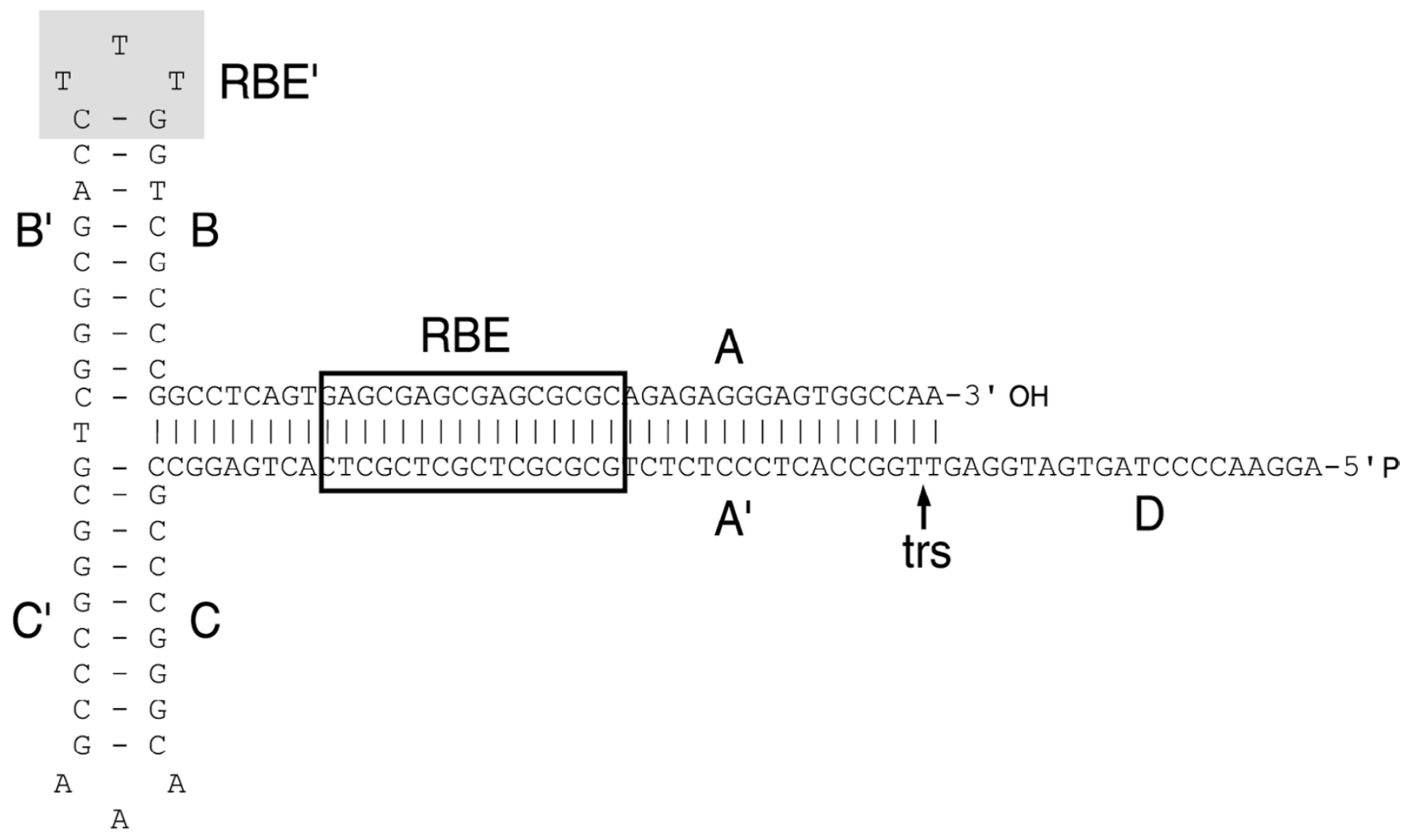

Figure 2

Secondary structure of the AAV2 ITR. The AAV2 ITR serves as origin of replication and is composed of two arm palindromes (B-B' and $C-C^{\prime}$ ) embedded in a larger stem palindrome (A-A'). The ITR can acquire two configurations (flip and flop). The flip (depicted) and flop configurations have the $\mathrm{B}-\mathrm{B}^{\prime}$ and the $\mathrm{C}^{-} \mathrm{C}^{\prime}$ palindrome closest to the $3^{\prime}$ end, respectively. The $\mathrm{D}$ sequence is present only once at each end of the genome thus remaining single-stranded. The boxed motif corresponds to the Rep-binding element (RBE) [1 19] where the AAV Rep78 and Rep68 proteins bind. The RBE consists of a tetranucleotide repeat with the consensus sequence 5'-GNGC-3'. The ATP-dependent DNA helicase activities of Rep78 and Rep68 remodel the A-A' region generating a stem-loop that locates at the summit the terminal resolution site (trs) in a single-stranded form $[120,|2|]$. In this configuration, the strand- and site-specific endonuclease catalytic domain of Rep78 and Rep68 introduces a nick at the trs. The shaded nucleotides at the apex of the T-shaped structure correspond to an additional RBE (RBE') [I2I] that stabilizes the association between the two largest Rep proteins and the ITR.

is thought to reflect the relative abundance of the two cap gene transcripts and the relative efficiency of translation initiation at the three start codons for the structural proteins. A conserved phospholipase $A_{2}$ (PLA2) motif, initially identified within the unique $\mathrm{N}$-terminal region of the parvoviral VP1 proteins [14], was also reported to have a biological significance in AAV2 infection [15]. Specifically, although dispensable for capsid assembly, DNA packaging, and virion internalisation, the VP1-embedded PLA2 activity seems to play a key role at some stage between the translocation of the AAV genome from the endocytic to the nuclear compartment and the initiation of viral gene expression [15]. Lately, mutational analysis of amino acid residues involved in AAV2 capsid pore architecture indicate that conformational changes of the virion structure during infection lead the VP1 $\mathrm{N}$ termini to protrude through the capsid pores inducing the PLA2 enzymatic activity needed for successful infection [13]. At the level of virion formation, immunofluorescence data shows that the VP1 and VP2 proteins are found primarily in the nuclei of infected cells, whereas VP3 is nearly evenly distributed between the nucleus and the cytoplasm [16]. However, in the presence of VP1 and/or VP2, VP3 accumulates in the nucleus suggesting transport of the major 


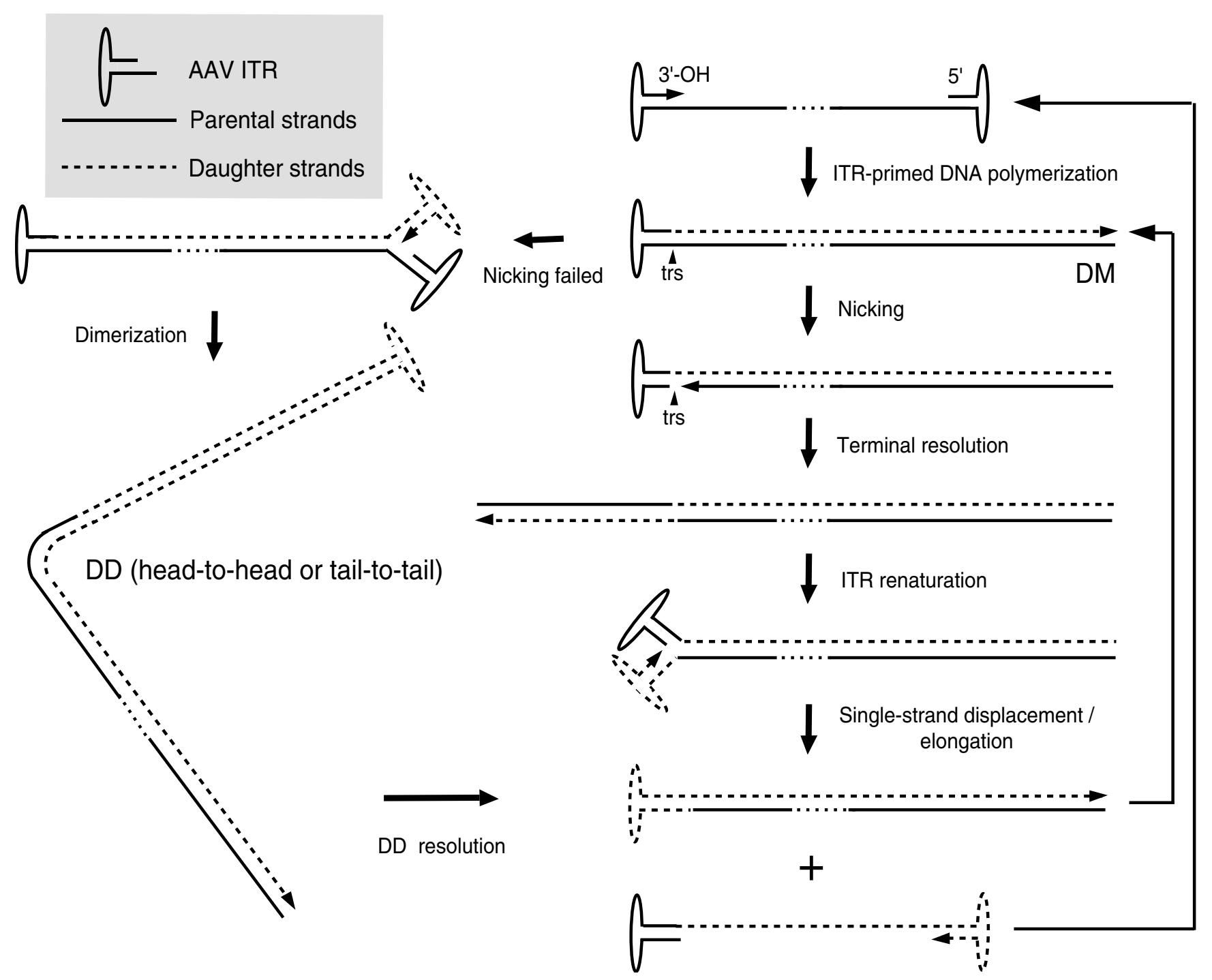

Figure 3

Schematic representation of the AAV DNA replication model. AAV DNA replication is thought to involve a self-priming singlestrand displacement mechanism that is initiated by DNA polymerisation at the 3 ' hairpin primer of input single-stranded genomes. This leads to the formation of linear unit-length double-stranded molecules (duplex monomers, DMs) with one covalently closed end. These structures are resolved at the terminal resolution site (trs) by site-specific nicking of the parental strand opposite the original 3' end position (i.e., at nucleotide 125). The newly generated free 3' hydroxyl groups provide a substrate for DNA polymerases that unwind and copy the inverted terminal repeat (ITR). Finally, the palindromic linear duplex termini can renaturate into terminal hairpins putting the 3' hydroxyl groups in position for single-strand displacement synthesis. Next, single-stranded genomes and new DM replicative forms are made. When nicking does not occur, elongation proceeds through the covalently closed hairpin structure generating linear double-length double-stranded molecules (duplex dimers, DDs) with either a head-to-head or a tail-to-tail configuration. The DD replicative intermediates can be resolved to DMs through the AAV ITR sequences located at the axis of symmetry.

capsid protein by association with the nuclear localization signal-bearing proteins VP1 and VP2 [17]. Immunofluorescence results suggest that capsid assembly is confined to the nucleoli of infected cells. The involvement of nucleolar chaperones in this process has been postulated [16].
Fully assembled AAV capsids enter the nucleoplasm in an AAV Rep-dependent manner. This redistribution of the structural proteins causes the co-localization of all ingredients necessary for infectious particle formation, i.e., capsids, Rep proteins and viral genomes. Indeed, the AAV 
DNA packaging process is though to take place in distinct regions of the nucleoplasm [16]. Selective AAV DNA encapsidation is presumably directed by protein-protein interactions between pre-formed empty capsids and complexes of Rep78 or Rep68 with the virus genome [18]. Next, the helicase domains of capsid-docked Rep52 and Rep40 proteins are proposed to act as molecular motors that unwind and transfer de novo synthesized singlestranded DNA into empty particles [19] through the pores located at the fivefold symmetry axes [13].

\section{Host cell infection}

AAV2 virions utilize as primary attachment receptor heparan sulphate proteoglycans [20] while internalisation is aided by the co-receptors $\alpha_{v} \beta_{5}$ integrin heterodimers [21], fibroblast growth factor receptor type 1 [22] and the hepatocyte growth factor receptor, c-Met [23]. The use of ubiquitous heparan sulphate proteoglycans as docking sites explains in part the well-known broad tropism of this virus that include, human, non-human primate, canine, murine and avian cell types. AAV5 and AAV4 also bind to charged carbohydrate moieties in the form of $\mathrm{N}$ - and $\mathrm{O}$ linked sialic acids, respectively [24]. Expression profiling of AAV5 permissive and non-permissive cells with cDNA microarrays led to the identification of platelet-derived growth factor receptor as another cellular determinant involved in AAV5 infection [25].

The events and processes that regulate the trafficking of AAV particles into the nucleus are still not fully understood, however, some findings have been reported. For instance, infection experiments in HeLa cells expressing a dominant-negative form of dynamin significantly reduced AAV2 entry $[26,27]$. These results indicate that one route by which this virus can poke through the plasma membrane involves receptor-mediated endocytosis via the formation of clathrin-coated pits. In addition, lysomotropic agents and proton pump inhibitors greatly hamper AAV2 infection suggesting that internalised virions escape from endosomes and are released in the cytosol by a low $\mathrm{pH}$-dependent process [27]. In addition, a powerful new imaging technique based on single-molecule labelling of discrete AAV particles enabled real-time monitoring of the trajectories of individual virions [28]. In these experiments, it was shown that each endosome carries a single AAV particle. Moreover, the abrogation of vectorial motion of virions in nocodazole-treated cells supported the involvement of microtubule assembly and motor proteins in active AAV intracellular transportation. Finally, it has been suggested that AAV particles due to their very small size can access the nucleus through the nuclear pore complex (NPC). However, recent research points to a nuclear entry process that is not dependent on NPC activity $[29,30]$ whereas the issue of whether AAV capsids enter nuclei intact or remodelled seems to depend on the presence or absence, respectively, of co-infecting helper Ad particles [30].

\section{Lytic and lysogenic pathways}

After entry into the host cell nucleus, AAV can follow either one of two distinct and interchangeable pathways of its life cycle: the lytic or the lysogenic. The former develops in cells infected with a helper virus such as Ad or herpes simplex virus (HSV) whereas the latter is established in host cells in the absence of a helper virus. When AAV infects a human cell alone, its gene expression program is auto-repressed and latency ensues by preferential integration of the virus genome into a region of roughly $2-\mathrm{kb}$ on the long arm (19q13.3-qter) of human chromosome 19 [31,32] designated AAVS1 [33]. Recent research showed that this locus is in the vicinity of the muscle-specific genes $p 85$ [34], TNNT1 and TNNI3 [35]. Furthermore, the AAVS1 sequence lies in a chromosomal region with characteristics of a transcription-competent environment [36]. Interestingly, an insulator within this locus was recently identified [37]. The targeted integration of the AAV genome, a phenomenon unique among all known eukaryotic viruses, enables the provirus DNA to be perpetuated through host cell division. Moreover, the level of specificity of this process of AAV biology (a single preintegration region within the entire human genome) makes its exploitation highly attractive for achieving the ultimate goal of safe and stable transgene expression [38].

Even if working models for the targeted DNA integration mechanism remain sketchy $[39,40]$, the viral components needed for the site-specific integration reaction have been identified. They are composed in cis by the AAV ITRs and in trans by either one of the two largest Rep proteins (i.e., Rep78 or Rep68). Recently, another cis-acting sequence was shown to be necessary for high-level site-specific DNA integration $[41,42]$. This sequence overlaps with the highly regulated p5 promoter and, like the ITR sequence, harbours an RBE.

Detailed genetic analyses using an AAVS1-containing episome system demonstrated that a 33-bp sequence containing elements related to the RBE and to the trs is sufficient for targeted DNA integration. Their functional relevance was demonstrated by the absence of targeted DNA integration into mutated substrates [39]. In addition, the AAVS1 region behaves as an origin of replication in the presence of Rep proteins both in vitro [43] and in vivo [44]. Finally, the AAVS1-specific RBE and trs are separated by a spacer element whose sequence and length affects the efficiency of the site-specific DNA integration reaction [45]. The human genome has numerous Rep binding sites. However, database searches have revealed that an RBE at a proper distance from a trs sequence occurs only in the AAVS1 locus, which is consistent with the 
specificity of the integration reaction revealed through biological assays [46]. Moreover, in vitro studies showed that via their interaction with the RBE sequences present in the AAV ITRs and in the AAVS1 locus, Rep78 and Rep68 proteins could tether viral to cellular DNA [47]. Although, as mentioned above, the actual mechanism evolved by AAV to target its DNA to the AAVS1 locus is currently unknown, taken together these observations provide at the molecular level an explanation for the specificity of the reaction and the requirement for RBE-containing sequences in cis and either one of the two largest Rep proteins in trans. Remarkably, only recently a study emerged directly addressing the AAV DNA integration efficiency and the correlation between random versus targeted integration levels [48]. Using a tissue culture system, the authors showed by clonal analyses of target cells and Southern blot hybridisations that $50 \%$ of infected cells were stably transduced by AAV when a multiplicity of infection of 100 was used. Raising the dose of virus increased neither the frequency of infected cells nor the integration levels. Although multiplicities of infection of 100 and 10 both yielded approximately $80 \%$ infected cells, the frequency of stably transduced cells was below $5 \%$ when employing the lower dose. Virtually all integration events targeted the AAVS1 locus. Finally, for each multiplicity of infection, the frequency of AAVS1 site disruption without accompanying DNA insertion was higher than the frequency of site-specific integration by a factor of 2 .

When a latently infected cell is super-infected with a helper virus, the AAV gene expression program is activated leading to the AAV Rep-mediated rescue (i.e., excision) of the provirus DNA from the host cell chromosome followed by replication and packaging of the viral genome. Finally, upon helper virus-induced cell lysis, the newly assembled virions are released. The induction of the lytic phase of the AAV life cycle from a stably integrated provirus can also occur in the absence of a helper virus, though with a lower efficiency, when the host cell is subjected to metabolic inhibitors and to DNA damaging agents such as UV irradiation or genotoxic compounds [49]. Moreover, in differentiated keratinocytes of an epithelial tissue culture system modelling skin, AAV2 was shown to initiate and proceed through a complete replicative cycle in the absence of helper viruses or genotoxic agents [50]. Taken together, these phenomena indicate that AAV is not defective in absolute terms.

\section{Adeno-associated virus vectorology General principle}

Historically, most recombinant AAV (rAAV) vectors have been based on serotype 2 (AAV2) that constitutes the prototype of the genus $[51,52]$. Important to those pursuing the use of rAAV for gene therapy applications is the defec- tiveness of the parental virus and its presumed non-pathogenic nature. The realization that a molecularly cloned AAV genome could in Ad-infected cells recapitulate the lytic phase of the AAV life cycle and give rise to infectious virions enabled not only the detailed genetic analyses of the virus but provided, in addition, a substrate to generate rAAV particles [53]. The latter task was facilitated by the fact that the AAV ITRs contain all cis-acting elements involved in genome rescue, replication and packaging. Furthermore, since the AAV ITRs are segregated from the viral encoding regions, rAAV design can follow the wholegene-removal or "gutless" vector rational of, for instance, retrovirus-based vectors in the sense that the cis-acting elements involved in genome amplification and packaging are in linkage with the heterologous sequences of interest, whereas the virus encoding sequences necessary for genome replication and virion assembly are provided in trans (Fig. 4). Typically, rAAV particles are generated by transfecting producer cells with a plasmid containing a cloned rAAV genome composed of foreign DNA flanked by the 145 nucleotide-long AAV ITRs and a construct expressing in trans the viral rep and cap genes. In the presence of Ad helper functions, the rAAV genome is subjected to the wild-type AAV lytic processes by being rescued from the plasmid backbone, replicated and packaged into preformed AAV capsids as single-stranded molecules.

\section{Production and purification strategies}

The Ad helper functions were originally supplied by infection of rAAV producer cells with a wild-type Ad (Fig. 4). Subsequent elimination of the helper virus from rAAV stocks relied on the distinct physical properties of AAV and Ad virions. In particular, differences in thermostability and density between AAV and Ad particles allowed the specific elimination of helper Ad virions by heat-inactivation (i.e., half-hour at $56^{\circ} \mathrm{C}$ ) and isopycnic cesium chloride density ultracentrifugation. The finding that $\mathrm{Ad}$ helper functions are provided by expression of $E 1 A, E 1 B$, E2A, E4ORF6 and VA RNAs, enabled subsequent Ad-free production of rAAV vector stocks by incorporating $V A$ RNAs, E2a and E4ORF6 sequences into a plasmid and transfecting it together with the rAAV DNA plus rep and cap templates into Ad E1A- and E1B-expressing cells [5456]. During the testing of new packaging plamids for rAAV production it was also found that reduction of the expression levels of the two largest AAV Rep proteins leads to an increase in vector yields $[56,57]$. Although these methods improve rAAV production and avoid the need for Ad infection, they are difficult to scale up due to their dependence on DNA transfection. The development of up-scalable transfection-independent methods for rAAV production have been fiercely pursued by the requirement for large amounts of highly purified vector particles to perform experiments in large animal models and human clinical trials. One of these transfection-independent 


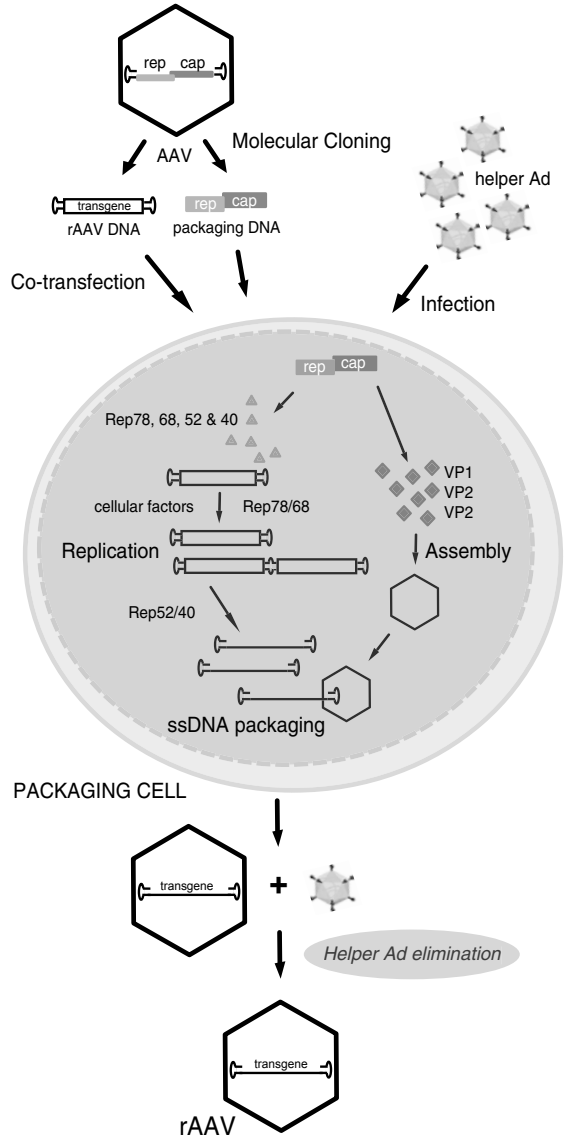

Figure 4

Overview of the initial recombinant AAV production system. The generation of the first infectious clones of AAV permitted functional dissection of the virus genome. This allowed the construction of plasmids encoding rAAV genomes in which the minimal complement of wild-type sequences necessary for genome replication and packaging (i.e., the AAV ITRs) frame a gene of interest (transgene) instead of the AAV rep and cap genes. When these constructs are transfected into packaging cells together with a rep and cap expression plasmid they lead to the production of rAAV particles. Helper activities required for the activation and support of the productive phase of the AAV life cycle were originally introduced by infection of the packaging cells with wild-type Ad as depicted. Current transfection-based production methods make use of recombinant DNA encoding the helper activities instead of Ad infection. Cellular DNA polymerase activities together with the Rep78 and Rep68 proteins lead to the accumulation of replicative intermediates both in the duplex monomer (DM) and duplex dimer (DD) forms. A fraction of this de novo synthesized DNA is incorporated in the single-stranded format into preformed empty capsids most likely through the catalytic activities of the Rep52 and Rep40 proteins. The resulting infectious rAAV virions are released from the producer cells together with helper Ad particles. Sequential heat treatment and buoyant density centrifugation allows the selective elimination of the helper virus from the final rAAV preparation. production strategies involves the generation of packaging cell lines having the AAV rep and cap genes stably integrated in their genomes. The establishment of effective, high-titer producer cell lines has proven difficult mainly due to the inhibitory effects of Rep proteins on cell growth [58] and the accumulation of low amounts of AAV gene products relative to a wild-type virus infection. Nonetheless, improvements in the control of rep expression through the development of stringent inducible gene expression systems can overcome the former hurdle [59] whereas in situ amplification of integrated rep and cap templates helps to minimize the latter problem $[60,61]$. Another transfection-independent approach to produce rAAV involves the delivery of the viral genes together with the rAAV DNA and the helper functions via infection of produced cells with recombinant viruses based on $\mathrm{Ad}$ [60], HSV [62] or baculovirus [63]. In parallel to new rAAV production platforms, insights into AAV biology are also leading to significant improvements in the quality and purity of vectors based on AAV2 as well as on those based on other serotypes. Specifically, knowledge on AAV receptor usage has permitted the implementation of upscalable affinity column chromatography purification schemes $[64,65]$. In addition, a more broadly applicable column chromatography procedure, based on the ionexchange principle, has recently been developed for the purification of rAAV2, rAAV4 and rAAV5 particles [66].

\section{Tropism modification}

An increasingly important area in the development of $\mathrm{AAV}$ as a vector concerns the engineering of altered cell tropisms to narrow or broaden rAAV-mediated gene delivery and to increase its efficiency in tissues refractory to AAV2 infection. Cells can be poorly transduced by prototype rAAV2 not only because of low receptor content but also owing to impaired intracellular virion trafficking and uncoating $[67,68]$ or single-to-double strand genome conversion [69-71]. Thus, considering that these processes depend either directly or indirectly on capsid conformation, cell targeting strategies determine not only the cell type(s) with which the vector interacts but also critically affect the efficiency of the whole gene transfer process.

Several of these approaches rely on the modification by chemical, immunological or genetic means of the AAV2 capsid structure endowing it with ligands that interact with specific cell surface molecules [72]. The fact that the atomic structure of AAV2 has recently been determined [2] provides a significant boon to those pursuing the rational design of targeted AAV vectors. Another route to alter rAAV tropism exploits the natural capsid diversity of newly isolated serotypes by packaging rAAV2 genomes into capsids derived from other human or non-human AAV isolates [73]. To this end, up until now, most researches employ hybrid trans-complementing 
constructs that encode rep from AAV2 whereas cap is derived from the serotype displaying the cell tropism of choice. This pseudotyping approach may also be beneficial in evading neutralizing antibodies to capsid components in individuals seropositive for AAV2 or in those in need of vector readministration. Finally, experiments published recently using rAAV2 genomes pseudotyped with coats from AAV6 [74] and AAV8 [75] revealed stunning gene transfer efficiencies when these vectors were administered alone at high doses or in combination with a blood vessel permeating agent. The authors could demonstrate transduction of the entire murine striated muscle system (e.g., diaphragm, heart and skeletal muscles) and of virtually $100 \%$ of the hepatocytes after a single intravenous injection. These body-wide transduction efficiencies raise both great perspectives as well as caution since they open new therapeutic avenues for diseases that require widespread gene delivery (e.g., muscular dystrophies) while, simultaneously, beg for stringent tissue-specific transcriptional control to minimize potential deleterious effects due to transgene expression in non-target tissues. Moreover, assuming similar avidity of these serotypes for human tissues, translation of these protocols from mice to patients will require vastly greater amounts of vector particles.

\section{Mechanisms of vector DNA persistence}

Knowledge on the mechanisms at play following rAAV transduction is building steadily over recent years mainly because of its direct relevance to the application of rAAV in therapeutic gene transfer. DNA vectored through rAAV can persist long-term in organs such as in the liver and the striated muscles of mice and dogs. Most importantly, data showing prolonged and stable expression of an increasing variety of transgenes in numerous animal models without notable toxicity is accumulating [76]. It are in fact these attributes of rAAV-based gene transfer that turns it into one of the most promising methods for somatic gene therapy providing a rational for the entry of these vectors into the clinical trial arena. However, at the outset it is important to refer that this stability does not arise due to foreign DNA insertion into the parental virus pre-integration site since the absence of rep gene products prevents DNA targeting to the AAVS1 locus. Moreover, because rAAV vectors lack viral genes altogether, the molecular fate of the DNA once in the nucleus is dependent on host cell activities (though a role for the virion capsomers cannot be ruled out). These cellular activities, that only recently have started to be identified, depend on the type as well as on the physiological status of the target cell. Finally, it is also of note that the single-stranded nature of AAV genomes implies that, before transgene expression can occur, the incoming rAAV DNA needs to be converted into a transcriptionally functional double-stranded template.
A recent study indicates that free (i.e., unpackaged) singlestranded rAAV genomes have a very transient presence in the target cell [67] either because the majority is recognized by host enzymes as damaged DNA and degraded or because, under certain conditions, single-to-double strand conversion occurs readily following uncoating. There are two pathways by which rAAV DNA can be converted from the single- to the double-stranded form each of them with its own set of supporting experimental data. One possible route develops through de novo secondstrand DNA synthesis from the hairpin at the 3 ' end of the genome (Fig. 2). Initial studies revealed that this step could be greatly enhanced by Ad E4ORF6 expression, UV irradiation or treatment of target cells with genotoxic chemicals $[69,70]$. Furthermore, a direct correlation between double-stranded template accumulation and gene expression was found. More recently, the phosphorylation status of a cellular protein named FKBP52 was shown to modulate the convertion of single-stranded rAAV DNA into double-stranded molecules both in tissue culture [77] and in murine hepatocytes [78]. FKBP52 phosphorylation by the epidermal growth factor receptor protein tyrosine kinase enables the molecule to bind the single-stranded AAV ITR D-sequence (Fig. 2). This binding activity correlates strongly with second-strand DNA synthesis inhibition. Conversely, in its dephosphorylated state, due to T-cell protein tyrosine phosphatase activity, FKBP52 does not bind vector genomes allowing synthesis of the complementary strand to occur with a subsequent increase in transgene expression levels.

As said before, single-stranded AAV genomes with sense (plus) and anti-sense (minus) orientations are packaged equally well. Therefore, another possible route involved in the generation of double-stranded DNA forms in target cells comprises the annealing of single-stranded molecules with opposing polarities. Evidence for the existence of this DNA synthesis-independent pathway came from experiments using rAAV genomes that were site-specifically methylated [71]. In these experiments restriction enzymes were used as probes to evaluate whether modified rAAV genomes extracted from murine livers were fully methylated (representing annealing products) or hemimethylated (corresponding to second-strand synthesis products). Thus, seemingly, a contention exits between advocates of DNA synthesis dependent and independent models. It is clear, however, that these two pathways are not necessarily mutually exclusive. In fact, recent experiments in cells under normal physiological conditions indicate that each of these pathways can contribute to the generation of transcriptionally active rAAV genomes [67]. For the latter experiments the authors resurrected a technique deployed to directly demonstrate that AAV is a single-stranded virus [8]. Exploiting the differential thymidine content of complementary polynucleotide 
chains they used incorporation of the thymidine analogue bromodeoxyuridine (BrdU) to physically separate plusfrom minus-strand containing rAAV particles following buoyant density centrifugation. Infection of indicator cells with each vector type led to reporter gene expression signifying the involvement of second-strand DNA synthesis and precluding an absolute requirement for plus and minus strand annealing. However, co-infection with both vector types originated higher numbers of cells expressing the reporter gene indicating that strand annealing contributes to the accumulation of double-stranded genomes [67].

Subsequently, duplex rAAV genomes can, throught intraor intermolecular recombination at the ITRs, originate circular forms or linear concatemers, respectively [71,79]. The circular episomes can also evolve into high-molecular-weight concatamers in a time-dependent manner [79]. The balance between linear versus circular forms is, at least in part, regulated by a complex containing DNAdependent protein kinase (DNA-PK) [80]. This complex plays a vital role in the repair of double-stranded chromosomal breaks and in V(D)J recombination by non-homologous end-joining (NHEJ). The absence of the catalytic subunit of DNA-PK (DNA-PKcs) in severe combined immunodeficient (SCID) mice (DNA-PKcs-negative) allowed Song and colleagues to demonstrate its involvement in circular rAAV episome formation in skeletal muscle [80]. Subsequent studies in liver and skeletal muscle of SCID and normal (DNA-PKcs-positive) mice have extended the observation that DNA-PK enhances the formation of rAAV circular episomes over linear forms $[81,82]$. It has been postulated that free double-stranded rAAV DNA ends are substrates for the cellular doublestranded break repair machinery responsible for freeended DNA removal through NHEJ ligation [80]. Notwithstanding their diverse topology and unit numbers, all these extrachromosomal DNA forms are transcriptioncompetent templates. Furthermore, they are thought to be responsible for the stable maintenance of transgene expression both in skeletal muscles [79] and in the lungs [83]. In the liver it has been shown that, in addition to the aforesaid episomal forms, circa $10 \%$ of the doublestranded rAAV genomes can be found inserted in the chromosomal DNA [84].

Backed by the complete mouse genome sequence, researchers could establish that a significant proportion of rAAV DNA integration events occur in regions that are transcriptionally active in murine hepatocytes [85]. In some instances, sequence micro-homologies and unrelated nucleotides are found at the truncated ITR-chromosomal DNA junctions. Moreover, rAAV DNA insertion is consistently associated with host chromosomal deletions. These characteristics resemble the "fingerprints" following double-stranded DNA break repair through NHEJ recombination. Thus, taken together, these results point to the involvement of NHEJ in rAAV DNA integration in addition to its putative role in the removal of free rAAV DNA ends, as previously discussed. This interpretation is further supported by previous and newly acquired data. For instance, earlier tissue culture studies revealed a direct correlation between genomic instability due to DNA-damaging agents or genetic defects and stable transduction by rAAV $[86,87]$. Other results showed that proteins belonging to the NHEJ complex bind to linear rAAV DNA [88]. More recently, a genetic approach permitted the deliberate induction of double-stranded chromosomal breaks within a predefined site [89]. The experimental set up consisted of retrovirus vector-mediated expression of the ISceI endonuclease in cells engineered with this enzyme's 18-bp recognition sequence. Following transduction of these cells with rAAV, the authors could demonstrate insertion of foreign DNA into I-Scel-induced doublestranded breaks. Characterization of vector-chromosome junctions revealed the telltale features observed after rAAV DNA integration into chromosomal breaks arising spontaneously at random sites. It is thus possible to speculate that rAAV proviral DNA is just another by-product of the mechanism the cell uses to eliminate free-ended substrates reminiscent of damaged DNA or invading nucleic acids (e.g., linear retroviral cDNA). As corollary, compared to the integrase-dependent retroviral genome integration, rAAV DNA insertion is a passive process that relies instead on pre-existent chromosomal breaks and host cell enzymes.

Chromosomal DNA integration with current vectors is a double-edged sword. On the one hand it provides a basis for permanent genetic correction while, on the other hand, raises safety issues related to insertional gene-inactivation and proto-oncogene deregulation. It is thus highly relevant for the clinical deployment of rAAV that these vectors do not create but instead insert into existing chromosomal breaks. The latter can be substrates for inaccurate NHEJ-mediated repair regardless of the presence of rAAV genomes. Therefore, concerns about insertional oncogenesis might be less for rAAV- than for retroviral vector-mediated gene transfer. Additionally, in contrast to retroviral vectors, rAAV vectors do not display "outward" promoter activity. Despite this, it is still conceivable that rAAV DNA insertion can lead to hazardous alteration of neighbouring gene(s) expression via vector-encoded regulatory sequences (e.g., enhancers). Thus, preventive measures such as judicious choice of transcriptional elements and use of insulators may turn out to be desirable or even indispensable in target tissues in which rAAV DNA is known to integrate at appreciable levels. Adding to the challenge these genetic elements have to be small enough 
to leave space needed to accommodate the gene of interest.

\section{Emerging technologies}

The small packaging capacity of AAV particles (about 4.7 $\mathrm{kb}$ ) [90] is considered one of the main limitations of rAAV vectors since it excludes therapeutically important coding sequences (e.g., dystrophin cDNA) and potent regulatory elements (e.g., albumin promoter). As discussed above, incoming linear rAAV genomes can form concatamers in target cells through intermolecular recombination at their free ends. This phenomenon has been successfully exploited to assemble in target cells large genetic messages through the joining of two independently transduced rAAV genomes each of which encompassing a portion of a large transcriptional unit. mRNA molecules encoding a functional protein are generated from the rAAV DNA head-to-tail heterodimers by splicing out the AAV ITR sequences from the primary transcripts (Fig. 5) [91]. Although this split gene strategy allows expression of almost double-sized transgenes after rAAV-mediated gene delivery, its efficiency is consistently lower than that observed with a single control vector encoding the fulllength transgene. Both vectors have to transduce the same cell and only heteroconcatamers with a head-to-tail organization will give rise to a functional full-length gene product. In addition, there are risks associated with the integration into host chromosomes of vectors encoding exclusively regulatory elements or truncated gene products. New work, however, suggests that some of these limitations and concerns can, at least partially, be addressed $[92,93]$.

Another development in rAAV design is the so-called selfcomplementary AAV vectors (scAAV) [94]. The scAAV approach builds on the ability of AAV to package replicons with half the size of the wild-type DNA in the form of single-stranded dimeric genomes with an inverted repeat configuration [95]. In the target cell, these selfcomplementary molecules can readily fold back into double-stranded forms without the need for de novo DNA synthesis or for the annealing of sense and antisense strands (Fig. 6). Ultimately, regardless of the mechanism(s) at play, scAAV lead to enhanced formation of transcriptioncompetent double-stranded genomes thus improving the expression kinetics and yields of vector-encoded products. This scAAV method was subsequently perfected by mutagenesis of one of the two trs sequences to force the generation of dimeric over monomeric replicative forms (Fig. 6) [96]. The main disadvantage of this approach is the need to limit the size of the transgenes that can be delivered to approximately half the length of the already small AAV genome. It is conceivable that this drawback can be tackled by coupling scAAV with heterodimerization strategies. Alternatively, long double-stranded rAAV genomes can be transferred into target cells via capsids of larger viruses such as Ad [97-100], baculovirus [101] or HSV [102]. In some of these hybrid viral vector systems, integration of the rAAV DNA into the AAVS1 locus on human chromosome 19 was accomplished by transient expression of AAV Rep activities in the target cells [38]. Targeted DNA integration is advantageous since it dispels the insertional oncogenesis concerns discussed above.

Site-specific or targeted DNA integration can also be achieved through homologous recombination (HR) between a transduced DNA fragment and an endogenous gene in the target cell genome. The ability to introduce precise genetic modifications in germ cells of mice combined with powerful selection markers has revolutionized mammalian genetics [103]. The same principle can be applied to achieve correction of defective genes in somatic human cells. In fact, targeted gene correction is conceptually an attractive alternative to gene addition since there is no strict need to transduce the entire gene and associated regulatory elements but only a fraction of the targeted gene sequence. In addition, the corrected gene remains in its chromosomal context thus being subject to the proper regulatory circuitry. However, gene targeting strategies are currently not practical mostly due to the inefficiency of HR after foreign DNA delivery (typical frequencies lie below $\left.10^{-6}\right)$. It has been demonstrated that rAAV can be tailored to introduce precise nucleotide alterations in the genome of human cells at frequencies approaching $1 \%$ when multiplicities of infection in the order of $10^{5}$ to $10^{6}$ infectious genomes per cell are used [104]. In these experiments, it was observed that for each targeted integration event 10 non-targeted DNA insertions occurred and that, in comparison with other methods, the HR process was less dependent on the extent of homology. More recently, this technology was successfully used in human mesenchymal stem cells to disrupt via HR a mutant COL1A1 allele coding for a dominant-negative type of collagen causing osteogenesis imperfecta [105].

\section{Clinical trials}

Data on safe and long-lasting rAAV-mediated transgene expression in organs of animal models of human disease such as lung, liver, central nervous system and eye, together with improvements in vector production and purification methods provided the rational for initiating clinical studies with rAAV vectors. Currently, these clinical trials are either in phase I or in phase II. The former studies aim at determining safety and often also maximum tolerable dose of the therapeutic agent, while the latter entail the assessment of its efficacy and have higher statistical significance to detect potential side effects. Ailments being targeted include Parkinson's disease, Canavan's disease, $\alpha 1$-antitrypsin deficiency, cystic fibrosis (cystic fibrosis transmembrane conductance regulator [CFTR] deficiency) 

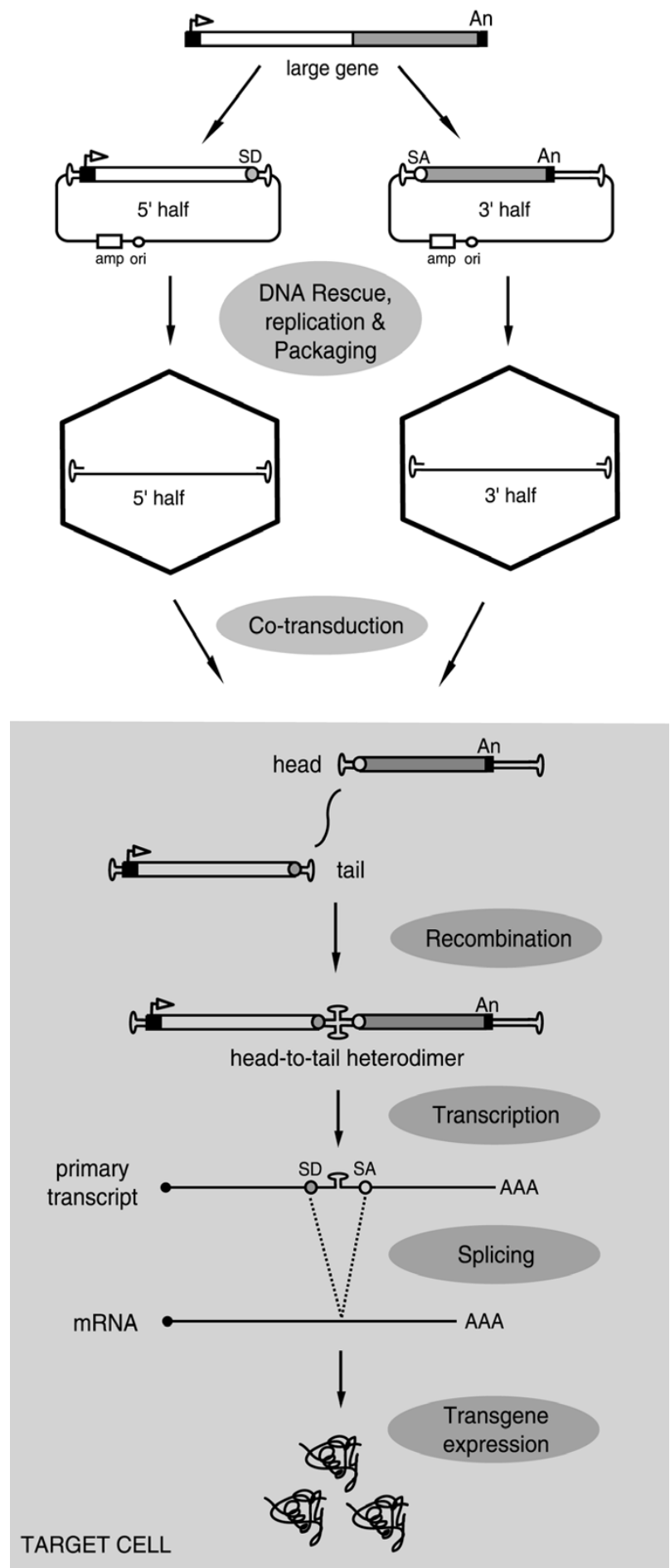

Figure 5

Diagram of the recombinant AAV split gene principle. An expression unit corresponding to a large gene is roughly divided in two halves. One of them consists of a promoter (solid box with arrowhead), the 5 ' half of the gene (open box) and a splice donor site (SD) while the other encodes a splice acceptor sequence (SA), the 3' portion of the gene (shaded box) and a polyadenylation signal (solid box). These fragments are independently cloned between two AAV ITRs. Vector stocks are then generated from the resulting shuttle plasmids and are used to co-transduce target cells. Head-to-tail heterodimerization via intermolecular recombination between the two vector DNA molecules restores the full-length expression unit and results in the synthesis of the desired protein after the splicing of the intervening AAV ITR sequences from the primary transcript. 

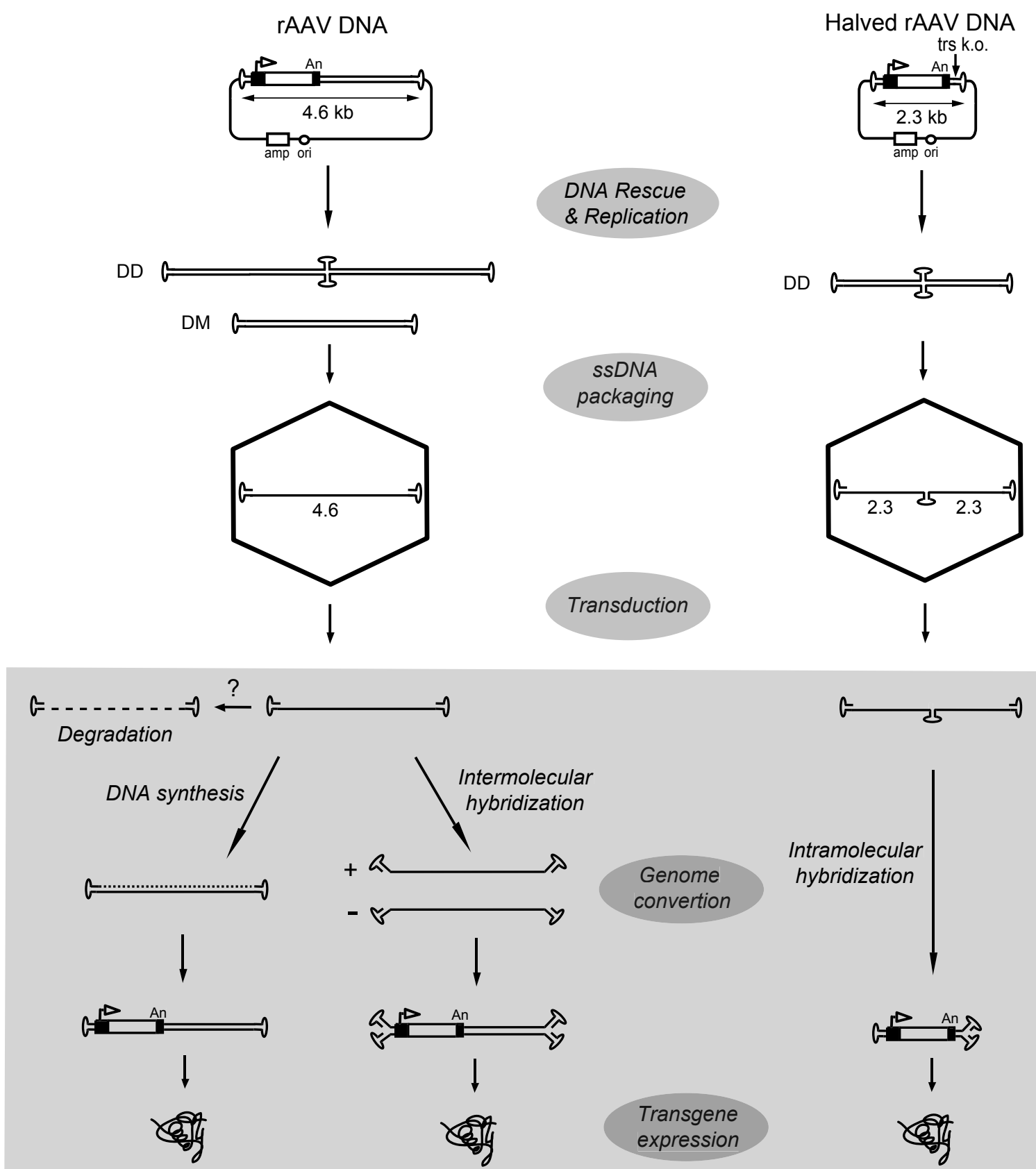

Target cell
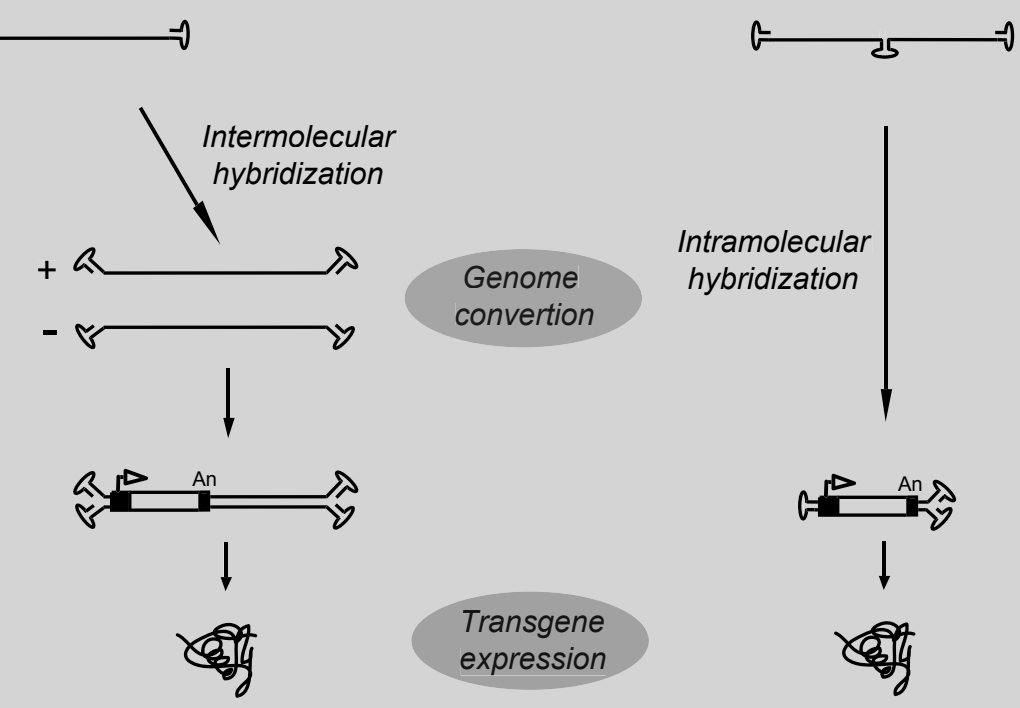

Intramolecular hybridization

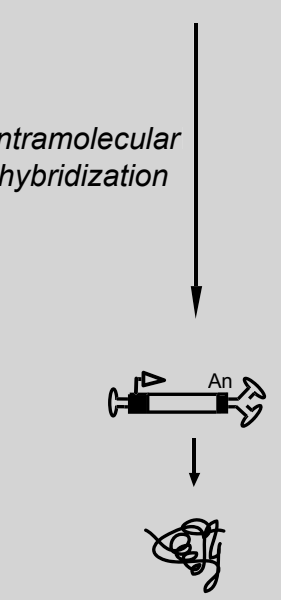

Figure 6

Diagram of the generation and transduction of a self-complementary AAV vector as compared to that of a conventional recombinant AAV. Left panel: According to the AAV DNA replication scheme, full-length rAAV genomes of both polarities are generated from duplex monomeric (DM) and duplex dimeric (DD) replicative intermediates and individually packaged in AAV capsids. In the nucleus of transduced cells the single-stranded genomes can either be a target for degradation or be converted into transcriptionally active double-stranded templates. The single-to-double strand DNA conversion depends on complementary chain synthesis or on the recruitment of a complementary genome (i.e., intermolecular hybridization). Right panel: According to the same replication model, a rAAV genome with roughly half the size of the wild-type AAV DNA and with one trs mutated, generates DD replicative intermediates with an inverted repeat configuration containing wild-type ITRs at the extremities and mutated ITRs at the axis of symmetry. Single-stranded molecules derived from these DNA structures are packaged in AAV capsids. After uncoating in the target cell nucleus, these molecules can readily fold into double-stranded templates through intramolecular base pairing due to their self-complementary nature (i.e., intramolecular hybridization). 
and hemophilia B (blood clotting factor IX [FIX] deficiency). Cystic fibrosis and hemophilia B are two examples of which more information is available. In fact, more than one decade ago, cystic fibrosis patients were the first human individuals subjected to rAAV administration [106].

Cystic fibrosis is the most common autosomal recessive disorder among Caucasians. The CFTR gene encodes a chloride channel that is essential for the transport of chloride ions across the membranes of epithelial cells of the lungs, gastrointestinal tract and sweat glands. The CFTR aids in the physiological transport of other ions and water. The pathophysiology of cystic fibrosis in the lung is not settled [107]. However, it seems uncontroversial that in the absence of functional CFTR, mucus of high viscosity and abnormal ionic content covers the airway epithelium leading to the accumulation of infectious agents. Chronic inflammation results in lung tissue damage and loss of respiratory function. Early death ensues.

As said before, all clinical trials are based on preclinical data retrieved from experiments in animal models. Unfortunately, CFTR knockout mice display primarily intestinal defects as opposed to the lung deterioration typical of the human condition. Accordingly, New Zealand white rabbits [108] and rhesus monkeys [109] constituted the major preclinical models for rAAV-mediated CFTR cDNA transfer. Overall, these studies showed that transduction with AAV2-based vectors led to prolonged and dosedependent CFTR cDNA expression in the respiratory tract after various modes of administration (e.g., direct bronchoscopic instillation and aerosol delivery). Importantly, no overt signs of vector-associated inflammation or toxicity were observed. Equally important, vector DNA was not detected in the gonads of any of the experimental animals tested, indicating that the risk of inadvertent germline transmission is very low. Initial clinical results showed rAAV2-mediated CFTR delivery to be well tolerated by human patients as well. It is also known from phase I dose-escalation studies that the aerosol method permits the delivery of vector DNA throughout the lung in a dosedependent manner. Although vector sequences persisted for up to 90 days at the highest dose, vector-specific transcripts could not be detected in the samples tested [110]. A follow up placebo-controlled phase II study incorporated into its design repeated administration of aerosolized vector particles. In addition to safety monitoring, this trial included the evaluation of proinflammatory cytokine interleukine-8 (IL-8) levels and pulmonary function. The treatment was well tolerated and, at days 30 and 14 , vector-treated patients showed evidence of improved lung function and reduced IL-8 concentrations in the sputum, respectively, when compared to placebo-treated individuals [111]. On the basis of these promising results new and expanded phase II clinical trials are currently underway.

In contrast to the mouse model of cystic fibrosis, FIX knockout mice and naturally occurring FIX-defective canines with missense and null mutations accurately mimic hemophilia B in humans. In addition, this Xlinked coagulopathy has other features that turn it into an attractive target for gene transfer approaches. Firstly, the limited size of the FIX cDNA (i.e., $2.8 \mathrm{~kb}$ ) allows the testing of a large variety of gene delivery systems including those with a small packaging capacity. Secondly, regulation of FIX expression is not needed because the encoded product has a broad therapeutic index and, importantly, concentrations above $1 \%$ of the physiological level start to be beneficial (i.e., < 1, 1 to 5 , and $>5 \%$ correspond to severe, moderate and mild disease, respectively). Finally, although the liver is the normal site of FIX production, synthesis and secretion of a biologically active form of this protein can also be achieved from ectopic, easily accessible, tissues such as skeletal muscle. Indeed, sustained dose-dependent therapeutic levels of canine FIX expression were attained in hemophilic dogs after both portal vein [112] and intramuscular [113] injections of rAAV2 particles. Partial phenotypic correction could be unambiguously established in these studies by measurement of hemostatic parameters such as the whole blood clotting time (WBCT) and the activated partial thromboplastin time (aPTT) lending support for the testing of rAAV2 in patients. In 1999, a dose-escalation phase I trial consisting of three dose cohorts (i.e., $2.0 \times 10^{11}, 6.0 \times$ $10^{11}$, and $1.8 \times 10^{12}$ vector genomes per kilogram of body weight) with three patients each was initiated. The readily accessible vastus lateralis muscle was chosen as target tissue for safety reasons. Results from these first parenteral administrations of rAAV in human subjects showed safe transfer of FIX without evidence for the formation of inhibitory antibodies to FIX and for the presence of vector sequences in semen. Gene transfer was detected by PCR and Southern blot analyses, whereas immunohistochemical staining of muscle biopsies revealed sustained transgene expression distributed mainly in slow twitch fibers [114]. However, this trial also showed that the doses tested were too low to bring about FIX plasma concentrations decisively above $1 \%$ of the normal value. It became apparent that therapeutic doses required numerous injections with more particles being administered per site. Several issues, however, blocked this approach. Firstly, the number of injections needed rendered the procedure impractical. Secondly, it was considered that saturation of the AAV2 receptors and of the capacity of myocytes to secrete FIX with the correct posttranslational modifications [115] would curtail the effect of using very high particle concentrations. Finally, and most importantly, a correlation was observed between injection of very high 
dosages of rAAV2 into muscle and the development of FIX neutralizing antibodies [113].

The next phase I trial targeted the liver of individuals with missense mutations by systemic administration of FIXencoding rAAV2. Unfortunately, this trial has been halted. Low vector doses were well tolerated but did not induce FIX levels above baseline, whereas high vector doses achieved only transient FIX expression and induced hepatotoxicity and immune responses against the vector and the transgene product [116]. Hopefully, new developments in rAAV technologies such as, vectors endowed with regulatory elements for high-level tissue-specific expression and higher liver and/or muscle tissue avidities will increase the therapeutic potency of rAAV-mediated FIX transfer in humans. Towards this goal, intraportal administration of an AAV8-based vector directing the synthesis of canine FIX through a liver-specific promoter achieved stable curative levels of the protein in naïve and in AAV2-preimmunized hemophilia B dogs (i.e., up to $26 \%$ and $16 \%$ of normal levels, respectively) [117]. The results obtained in AAV2-pretreated dogs are particularly significant if one considers that a significant proportion of humans have high AAV2 neutralizing antibody titers [118].

\section{Conclusion}

Important strides have recently been made in the optimisation of rAAV technology at the levels of production and performance. Insights from AAV biology have been instrumental in this process and are expected to continue to be the main catalyst behind the further development and efficacious deployment of rAAV. Most of the features initially identified in AAV as being highly desirable in a therapeutic gene carrier such as the seemingly nonpathogenic nature of the wild-type virus and its ability to infect, nondividing, terminally differentiated cells remain valid and contribute to put rAAV at the forefront of all vector systems that aim at safe and sustained transgene expression in vivo. A notable exception of an AAV attribute not retained by rAAV concerns the loss of AAVS1-targeted DNA integration.

The number of promising reports documenting rAAVmediated stable transgene expression in immunocompetent recipients is steadily increasing. However, the vast majority of these results have been obtained in inbred rodent models with relatively little genetic diversity. There are several indications (e.g., from research on rAAV-mediated FIX transfer) that the results obtained in mice cannot predict the outcome of experiments carried out in patients. This underscores the need not only for continuous improvement of the vectors themselves but also for deepening the knowledge about vector-host interactions outside the realm of rodent models. The ultimate goal of this research is to accomplish unequivocal clinical benefit by the identification of limitations and corresponding solutions to each particular disease-transgene-vector trilogy.

\section{Competing interests}

The author(s) declare that they have no competing interests.

\section{Acknowledgements}

I am grateful to Drs. Antoine A.F. de Vries, Shoshan-Knaän Shanzer and Maria Grazia Pau for their critical comments to this manuscript and to my lab colleagues for their enthusiasm and help. I thank Dr. Maria Grazia Pau and Maarten Holkers for making available the images depicted in figure I and 2, respectively. I am also thankful to the Fundação Portuguesa para a Ciência e Tecnologia and the Prinses Beatrix Fonds for neuromuscular diseases for previous (PRAXIS XXI/BD/9157/96) and current grants (MAR040222), respectively.

\section{References}

I. Atchison RW, Castro BC, Hammon WM: Adenovirus-associated defective virus particles. Science 1965, I49:754-756.

2. Xie Q, Bu W, Bhatia S, Hare J, Somasundaram T, Azzi A, Chapman MS: The atomic structure of adeno-associated virus (AAV-2), a vector for human gene therapy. Proc Natl Acad Sci USA 2002, 99: 10405-10410.

3. Koczot FJ, Carter BJ, Garon CF, Rose JA: Self-complementarity of terminal sequences within plus or minus strands of adenovirus-associated virus DNA. Proc Natl Acad Sci USA 1973, 70:215-219.

4. Berns KI: Parvovirus replication. Microbiol Rev 1990, 54:3 16-329.

5. Ni T-H, McDonald WF, Zolotukhin I, Melendy T, Waga S, Stillman B, Muzyczka N: Cellular proteins required for adeno-associated virus DNA replication in the absence of adenovirus coinfection. J Virol 1998, 72:2777-2787.

6. Pereira DJ, McCarty DM, Muzyczka N: The adeno-associated virus (AAV) Rep protein acts as both a repressor and an activator to regulate AAV transcription during a productive infection. J Virol 1997, 71:1079-1088.

7. Chejanovsky N, Carter BJ: Mutagenesis of an AUG codon in the adeno-associated virus rep gene: effects on viral DNA replication. Virology 1989, I73:120-128.

8. Berns KI, Adler S: Separation of two types of adeno-associated virus particles containing complementary polynucleotide chains. J Virol 1972, 9:394-396.

9. Berns KI, Giraud C: Biology of adeno-associated virus. Curr Top Microbiol Immunol 1996, 2 I 8: I-23.

10. Im DS, Muzyczka N: The AAV origin binding protein Rep68 is an ATP-dependent site-specific endonuclease with DNA helicase activity. Cell 1990, 6 I:447-457.

II. Smith RH, Kotin RM: The Rep52 gene product of adeno-associated virus is a DNA helicase with 3 '-to-5' polarity. J Virol 1998 , 72:4874-488I.

12. Collaco RF, Kalman-Maltese V, Smith AD, Dignam JD, Trempe JP: A biochemical characterization of the adeno-associated virus rep40 helicase. J Biol Chem 2003, 278:340 I I-340I7.

13. Bleker S, Sonntag F, Kleinschmidt JA: Mutational analysis of narrow pores at the fivefold symmetry axes of adeno-associated virus type 2 capsids reveals a dual role in genome packaging and activation of phospholipase A2 activity. J Virol 2005, 79:2528-2540.

14. Zádori Z, Szelei J, Lacoste M-C, Li Y, Gariépy S, Raymond P, Allaire $M$, Nabi IR, Tijssen P: A viral phospholipase $A_{2}$ is required for parvovirus infectivity. Dev Cell 200I, I:291-302.

15. Girod A, Wobus CE, Zádori Z, Ried M, Leike K, Tijssen P, Kleinschmidt JA, Hallek M: The VPI capsid protein of adeno-associated virus type 2 is carrying a phospholipase $A 2$ domain required for virus infectivity. J Gen Virol 2002, 83:973-978. 
16. Wistuba A, Kern A, Weger S, Grimm D, Kleinschmidt J: Subcellular compartmentalization of adeno-associated virus type 2 assembly. J Virol 1997, 71:134I-I352.

17. Ruffing $M$, Zentgraf $H$, Kleinschmidt JA: Assembly of viruslike particles by recombinant structural proteins of adeno-associated virus type 2 in insect cells. J Virol 1992, 66:6922-6930.

18. Im DS, Muzyczka N: Factors that bind to adeno-associated virus terminal repeats. J Virol 1989, 63:3095-3104.

19. King JA, Dubielzig R, Grimm D, Kleinschmidt JA: DNA helicasemediated packaging of adeno-associated virus type 2 genomes into preformed capsids. EMBO J 200I, 20:3282-329I.

20. Summerford C, Samulski RJ: Membrane-associated heparan sulfate proteoglycan is a receptor for adeno-associated virus type 2 virions. J Virol 1998, 72: 1438-1445

2I. Summerford C, Bartlett JS, Samulski RJ: $\alpha$ V $\beta 5$ integrin: a co-receptor for adeno-associated virus type 2 infection. Nat Med 1999, 5:78-82.

22. Qing K, Mah C, Hansen J, Zhou S, Dwarki V, Srivastava A: Human fibroblast growth factor $I$ is a co-receptor for infection by adeno-associated virus 2. Nat Med 1999, 5:7I-77.

23. Kashiwakura Y, Tamayose K, Iwabuchi K, Hirai Y, Shimada T, Matsumoto K, Nakamura T, Oshimi K, Daida H: Hepatocyte growth factor receptor is a coreceptor for adeno-associated virus type 2 infection. J Virol 2005, 79:609-6I4

24. Kaludov N, Brown KE, Walters RW, Zabner J, Chiorini JA: Adenoassociated virus serotype 4 (AAV4) and AAV5 both require sialic acid binding for hemagglutination and efficient transduction but differ in sialic acid linkage specificity. J Virol 200 I, 75:6884-6893

25. Di Pasquale G, Davidson BL, Stein CS, Martins I, Scudiero D, Monks A, Chiorini JA: Identification of PDGFR as a receptor for AAV5 transduction. Nat Med 2003, 9: | 306-13/2.

26. Duan D, Li Q, Kao AW, Yue Y, Pessin JE, Engelhardt JF: Dynamin is required for recombinant adeno-associated virus type 2 infection. J Virol 1999, 73:1037I-10376.

27. Bartlett JS, Wilcher R, Samulski RJ: Infectious entry pathway of adeno-associated virus and adeno-associated virus vectors. I Virol 2000, 74:2777-2785.

28. Seisenberger G, Ried MU, Endreß T, Büning H, Hallek M, Bräuchle $C$ Real-time single-molecule imaging of the infection pathway of an adeno-associated virus. Science 2001, 294:1929-1932.

29. Hansen J, Qing K, Srivastava A: Infection of purified nuclei by adeno-associated virus 2. Mol Ther 200I, 4:289-296.

30. Xiao W, Warrington KH Jr, Hearing P, Hughes J, Muzyczka N: Adenovirus-facilitated nuclear translocation of adeno-associated virus type 2. J Virol 2002, 76: II505-II5I7.

31. Kotin RM, Siniscalco M, Samulski RJ, Zhu XD, Hunter L, Laughlin CA McLaughlin S, Muzyczka N, Rocchi M, Berns KI: Site-specific integration by adeno-associated virus. Proc Natl Acad Sci USA 1990 87:22II-22।5.

32. Samulski RJ, Zhu X, Xiao X, Brook JD, Housman DE, Epstein N, Hunter LA: Targeted integration of adeno-associated virus (AAV) into human chromosome 19. EMBO J |99|, I0:394I-3950. erratum I I:I228

33. Kotin RM, Menninger JC, Ward DC, Berns KI: Mapping and direct visualization of a region-specific viral DNA integration site on chromosome 19q 13-qter. Genomics 1991, 10:831-834.

34. Tan I, $\mathrm{Ng} \mathrm{CH}$, Lim L, Leung T: Phosphorylation of a novel myosin binding subunit of protein phosphatase I reveals a conserved mechanism in the regulation of actin cytoskeleton. J Biol Chem 200I, 276:21209-21216.

35. Dutheil N, Shi F, Dupressoir T, Linden RM: Adeno-associated virus site-specifically integrates into a muscle-specific DNA region. Proc Natl Acad Sci USA 2000, 97:4862-4866.

36. Lamartina S, Sporeno E, Fattori E, Toniatti C: Characteristics of the adeno-associated virus preintegration site in human chromosome 19: open chromatin conformation and transcription-competent environment. J Virol 2000, 74:767I-7677.

37. Ogata T, Kozuka T, Kanda T: Identification of an insulator in AAVSI, a preferred region for integration of adeno-associated virus DNA. J Virol 2003, 77:9000-9007.

38. Owens RA: Second generation adeno-associated virus type 2based gene therapy systems with the potential for preferential integration into AAVSI. Curr Gene Ther 2002, 2: I45-159.
39. Linden RM, Winocour E, Berns Kl: The recombination signals for adeno-associated virus site-specific integration. Proc Natl Acad Sci USA 1996, 93:7966-7972.

40. Young SM Jr, Samulski RJ: Adeno-associated virus (AAV) sitespecific recombination does not require a Rep-dependent origin of replication within the AAV terminal repeat. Proc Nat Acad Sci USA 200I, 98: I3525-13530.

41. Philpott NJ, Giraud-Wali C, Dupuis C, Gomos J, Hamilton H, Berns $\mathrm{KI}$, Falck-Pedersen $\mathrm{E}$ : Efficient integration of recombinant adeno-associated virus DNA vectors requires a p5-rep sequence in cis. J Virol 2002, 76:54II-542I.

42. Philpott NJ, Gomos J, Berns KI, Falck-Pedersen E: A p5 integration efficiency element mediates Rep-dependent integration into AAVSI at chromosome 19. Proc Natl Acad Sci USA 2002, 99: $1238 \mid-12385$

43. Urcelay E, Ward P, Wiener SM, Safer B, Kotin RM: Asymmetric replication in vitro from a human sequence element is dependent on adeno-associated virus Rep protein. J Virol I995, 69:2038-2046.

44. Young SM Jr, McCarty DM, Degtyareva N, Samulski RJ: Roles of adeno-associated virus Rep protein and human chromosome 19 in site-specific recombination. J Virol 2000, 74:3953-3966.

45. Meneses $\mathrm{P}$, Berns $\mathrm{KI}$, Winocour E: DNA sequence motifs which direct adeno-associated virus site-specific integration in a model system. J Virol 2000, 74:62। 3-62 I6.

46. Wonderling RS, Owens RA: Binding sites for adeno-associated virus Rep proteins within the human genome. J Virol 1997, 71:2528-2534.

47. Weitzman MD, Kyöstiö SRM, Kotin RM, Owens RA: Adeno-associated virus (AAV) Rep proteins mediate complex formation between AAV DNA and its integration site in human DNA. Proc Natl Acad Sci USA 1994, 91 :5808-58I 2.

48. Hamilton H, Gomos J, Berns KI, Falck-Pedersen E: Adeno-associated virus site-specific integration and AAVSI disruption. Virol 2004, 78:7874-7882

49. Yalkinoglu AO, Heilbronn R, Burkle A, Schlehofer JR, zur Hausen $\mathrm{H}$ : DNA amplification of adeno-associated virus as a response to cellular genotoxic stress. Cancer Res 1988, 48:3 I 23-3 I 29

50. Meyers C, Mane M, Kokorina N, Alam S, Hermonatt PL: Ubiquitous human adeno-associated virus type 2 autonomously replicates in differentiating keratinocytes of a normal skin model. Virology 2000, 272:338-346.

5I. Hermonat PL, Muzyczka N: Use of adeno-associated virus as a mammalian DNA cloning vector: transduction of neomycin resistance into mammalian tissue cultured cells. Proc Natl Acad Sci USA 1984, 8 I:6466-6470.

52. Tratschin JD, West MH, Sandbank T, Carter BJ: A human parvovirus, adeno-associated virus, as a eukaryotic vector: transient expression and encapsidation of the prokaryotic gene for chloramphenicol acetyltransferase. Mol Cell Biol 1984, 4:2072-208I.

53. Samulski RJ, Berns KI, Tan M, Muzyczka N: Cloning of adeno-associated virus into pBR322: rescue of intact virus from the recombinant plasmid in human cells. Proc Natl Acad Sci USA 1982, 79:2077-208I.

54. Grimm D, Kern A, Rittner K, Kleinschmidt JA: Novel tools for production of recombinant adenoassociated virus vectors. Hum Gene Ther 1998, 9:2745-2760.

55. Matsushita T, Elliger S, Elliger C, Podsakoff G, Villarreal L, Kurtzman G], Iwaki Y, Colosi P: Adeno-associated virus vectors can be efficiently produced without helper virus. Gene Ther 1998 5:938-945.

56. Xiao X, Li J, Samulski RJ: Production of high-titer recombinant adeno-associated virus vectors in the absence of helper adenovirus. J Virol 1998, 72:2224-2232.

57. Li J, Samulski RJ, Xiao X: Role for highly regulated rep gene expression in adeno-associated virus vector production. J Virol 1997, 71:5236-5243.

58. Saudan P, Vlach J, Beard P: Inhibition of S-phase progression by adeno-associated virus Rep78 protein is mediated by hypophosphorylated pRb. EMBO J 2000, 19:435I-436I.

59. Qiao C, Wang B, Zhu X, Li J, Xiao X: A novel gene expression control system and its use in stable high-titer 293 cell-based adeno-associated virus packaging cell lines. J Virol 2002, 76:130|5-13027. 
60. Gao GP, Qu G, Faust LZ, Engdahl RK, Xiao W, Hughes JV, Zoltick $P W$, Wilson JM: High-titer adeno-associated viral vectors from a Rep/Cap cell line and hybrid shuttle virus. Hum Gene Ther 1998, 9:2353-2362.

6I. Chadeuf G, Favre D, Tessier J, Provost N, Nony P, Kleinschmidt J, Moullier $P$, Salvetti A: Efficient recombinant adeno-associated virus production by a stable rep-cap HeLa cell line correlates with adenovirus-induced amplification of the integrated repcap genome. J Gene Med 2000, 2:260-268.

62. Conway JE, Rhys CM, Zolotukhin I, Zolotukhin S, Muzyczka N, Hayward GS, Byrne BJ: High-titer recombinant adeno-associated virus production utilizing a recombinant herpes simplex virus type I vector expressing AAV-2 Rep and Cap. Gene Ther 1999, 6:986-993.

63. Urabe M, Ding C, Kotin RM: Insect cells as a factory to produce adeno-associated virus type 2 vectors. Hum Gene Ther 2002, I 3:1935-1943.

64. Auricchio A, Hildinger M, O'Connor E, Gao GP, Wilson JM: Isolation of highly infectious and pure adeno-associated virus type 2 vectors with a single-step gravity-flow column. Hum Gene Ther 200I, I 2:71-76.

65. Auricchio A, O'Connor E, Hildinger M, Wilson JM: A single-step affinity column for purification of serotype-5 based adenoassociated viral vectors. Mol Ther 200I, 4:372-374.

66. Kaludov N, Handelman B, Chiorini JA: Scalable purification of adeno-associated virus type 2, 4, or 5 using ion-exchange chromatography. Hum Gene Ther 2002, I 3: I235-I 243.

67. Hauck B, Zhao W, High K, Xiao W: Intracellular viral processing, not single-stranded DNA accumulation, is crucial for recombinant adeno-associated virus transduction. J Virol 2004, 78: $13678-13686$

68. Thomas CE, Storm TA, Huang Z, Kay MA: Rapid uncoating of vector genomes is the key to efficient liver transduction with pseudotyped adeno-associated virus vectors. J Virol 2004 78:3110-3122

69. Ferrari FK, Samulski T, Shenk T, Samulski RJ: Second-strand synthesis is a rate-limiting step for efficient transduction by recombinant adeno-associated virus vectors. I 996. J Virol 1996, 70:3227-3234

70. Fisher KJ, Gao GP, Weitzman MD, DeMatteo R, Burda JF, Wilson JM: Transduction with recombinant adeno-associated virus for gene therapy is limited by leading-strand synthesis. J Virol 1996, 70:520-532

7I. Nakai H, Storm TA, Kay MA: Recruitment of single-stranded recombinant adeno-associated virus vector genomes and intermolecular recombination are responsible for stable transduction of liver in vivo. J Virol 2000, 74:945 I-9463.

72. Rabinowitz JE, Samulski RJ: Building a better vector: the manipulation of AAV virions. Virology 2000, 278:30I-308.

73. Grimm D, Kay MA: From virus evolution to vector revolution use of naturally occurring serotypes of adeno-associated virus (AAV) as novel vectors for human gene therapy. Curr Gene Ther 2003, 3:28I-304.

74. Gregorevic P, Blankinship MJ, Allen JM, Crawford RW, Meuse L, Miller DG, Russell DW, Chamberlain JS: Systemic delivery of genes to striated muscles using adeno-associated viral vectors. Nat Med 2004, 1 0:828-834.

75. Nakai H, Fuess S, Storm TA, Muramatsu S-i, Nara Y, Kay MA: Unrestricted hepatocyte transduction with adeno-associated virus serotype 8 vectors in mice. J Virol 2005, 79:2। 4-224.

76. Buning $H$, Nicklin SA, Perabo L, Hallek M, Baker AH: AAV-based gene transfer. Curr Opin Mol Ther 2003, 5:367-375.

77. Qing K, Hansen J, Weigel-Kelley KA, Tan M, Zhou S, Srivastava A Adeno-associated virus type 2-mediated gene transfer: role of cellular FKBP52 protein in transgene expression. J Virol 200I, 75:8968-8976

78. Zhong L, Li W, Yang Z, Chen L, Li Y, Oing K, Weigel-Kelley KA Yoder MC, Shou W, Srivastava A: Improved transduction of primary murine hepatocytes by recombinant adeno-associated virus 2 vectors in vivo. Gene Ther 2004, I I: I I 65- | I 69.

79. Yang J, Zhou W, Zhang Y, Zidon T, Ritchie T, Engelhardt JF: Concatamerization of adeno-associated virus circular genome occurs through intermolecular recombination. J Virol 1999. 73:9468-9477.
80. Song S, Laipis PJ, Berns KI, Flotte TR: Effect of DNA-dependent protein kinase on the molecular fate of the rAAV2 genome in skeletal muscle. Proc Natl Acad Sci USA 200I, 98:4084-4088.

81. Nakai H, Storm TA, Fuess S, Kay MA: Pathways of removal of free DNA vector ends in normal and DNA-PKcs-deficient SCID mouse hepatocytes transduced with rAAV vectors. Hum Gene Ther 2003, | 4:87|-88|.

82. Duan D, Yue Y, Engelhardt JF: Consequences of DNA-dependent protein kinase catalytic subunit deficiency on recombinant adeno-associated virus genome circularization and heterodimerization in muscle tissue. J Virol 2003, 77:475 I-4759.

83. Afione SA, Conrad CK, Kearns WG, Chunduru S, Adams R, Reynolds TC, Guggino WB, Cutting GR, Carter BJ, Flotte TR: In vivo model of adeno-associated virus vector persistence and rescue. Virol 1996, 70:3235-324I.

84. Nakai H, Yant SR, Storm TA, Fuess S, Meuse L, Kay MA: Extrachromosomal recombinant adeno-associated virus vector genomes are primarily responsible for stable liver transduction in vivo. J Virol 2001, 75:6969-6976.

85. Nakai H, Montini E, Fuess S, Storm TA, Grompe M, Kay MA: AAV serotype 2 vectors preferentially integrate into active genes in mice. Nat Genet 2003, 34:297-302.

86. Alexander IE, Russell DW, Miller AD: DNA-damaging agents greatly increase the transduction of nondividing cells by adeno-associated virus vectors. J Virol I994, 68:8282-8287.

87. Sanlioglu S, Benson P, Engelhardt JF: Loss of ATM function enhances adeno-associated virus transduction and integration through pathways similar to UV irradiation. Virology 2000 , 268:68-78.

88. Zentilin L, Marcello A, Giacca M: Involvement of cellular doublestranded DNA break binding proteins in processing of the recombinant adeno-associated virus genome. J Virol 200I, 75: $12279-12287$

89. Miller DG, Petek LM, Russell DW: Adeno-associated virus vectors integrate at chromosome breakage sites. Nat Genet 2004, 36:767-773.

90. Dong JY, Fan PD, Frizzell RA: Quantitative analysis of the packaging capacity of recombinant adeno-associated virus. Hum Gene Ther 1996, 7:2101-2112.

91. Yan Z, Ritchie TC, Duan D, Engelhardt JF: Recombinant AAVmediated gene delivery using dual vector heterodimerization. In Methods in Enzymology Edited by: Phillips MI. San Diego: Academic Press; 2002:334-357. [Abelson JN and Simon MI (Series Editors): Gene Therapy Methods, vol 346.]

92. Reich SJ, Auricchio A, Hildinger M, Glover E, Maguire AM, Wilson JM, Bennett J: Efficient trans-splicing in the retina expands the utility of adeno-associated virus as a vector for gene therapy. Hum Gene Ther 2003, I 4:37-44.

93. Yan Z, Zak R, Zhang Y, Engelhardt JF: Inverted terminal repeat sequences are important for intermolecular recombination and circularization of adeno-associated virus genomes. J Virol 2005, 79:364-379.

94. McCarty DM, Monahan PE, Samulski RJ: Self-complementary recombinant adeno-associated virus (scAAV) vectors promote efficient transduction independently of DNA synthesis. Gene Ther 200I, 8: 1248-I254.

95. De la Maza LM, Carter BJ: Molecular structure of adeno-associated virus variant DNA. J Biol Chem 1980, 255:3194-3203.

96. McCarty DM, Fu H, Monahan PE, Toulson CE, Naik P, Samulski RJ: Adeno-associated virus terminal repeat (TR) mutant generates self-complementary vectors to overcome the rate-limiting step to transduction in vivo. Gene Ther 2003, I 0:2 I I 2-2 I I8.

97. Fisher KJ, Kelley WM, Burda JF, Wilson JM: A novel adenovirusadeno-associated virus hybrid vector that displays efficient rescue and delivery of the AAV genome. Hum Gene Ther 1996 7:2079-2087.

98. Lieber A, Steinwaerder DS, Carlson CA, Kay MA: Integrating adenovirus-adeno-associated virus hybrid vectors devoid of all viral genes. J Virol 1999, 73:93|4-9324

99. Recchia A, Parks RJ, Lamartina S, Toniatti C, Pieroni L, Palombo F, Ciliberto G, Graham FL, Cortese R, La Monica N, Colloca S: Sitespecific integration mediated by a hybrid adenovirus/adenoassociated virus vector. Proc Natl Acad Sci USA 1999, 96:2615-2620.

100. Gonçalves MA, Pau MG, de Vries AA, Valerio D: Generation of a high-capacity hybrid vector: packaging of recombinant ade- 
noassociated virus replicative intermediates in adenovirus capsids overcomes the limited cloning capacity of adenoassociated virus vectors. Virology 200I, 288:236-246.

10I. Palombo F, Monciotti A, Recchia A, Cortese R, Ciliberto G, La Monica N: Site-specific integration in mammalian cells mediated by a new hybrid baculovirus-adeno-associated virus vector. J Virol 1998, 72:5025-5034

102. Johnston KM, Jacoby D, Pechan PA, Fraefel C, Borghesani P, Schuback D, Dunn RJ, Smith FI, Breakefield XO: HSVIAAV hybrid amplicon vectors extend transgene expression in human glioma cells. Hum Gene Ther 1997, 8:359-370.

103. Capecchi MR: Altering the genome by homologous recombination. Science 1989, 244:1288-1292.

104. Russell DW, Hirata RK: Human gene targeting by viral vectors. Nat Genet 1998, 18:325-330.

105. Chamberlain JR, Schwarze U, Wang P-P, Hirata RK, Hankenson KD, Pace JM, Underwood RA, Song KM, Sussman M, Byers PH, Russell DW: Gene targeting in stem cells from individuals with osteogenesis imperfecta. Science 2004, 303:1 I98-I20I.

106. Flotte TR, Carter B, Conrad C, Guggino W, Reynolds T, Rosenstein B, Taylor G, Walden S, Wetzel R: A phase I study of an adenoassociated virus-CFTR gene vector in adult $C F$ patients with mild lung disease. Hum Gene Ther 1996, 7: | |45-1 I59.

107. Guggino WB: Cystic fibrosis and the salt controversy. Cell 1999 , 96:607-610.

108. Flotte TR, Afione SA, Conrad C, McGrath SA, Solow R, Oks H, Zeitlin $\mathrm{PL}$, Guggino WB, Carter BJ: Stable in vivo expression of the cystic fibrosis transmembrane conductance regulator with an adeno-associated virus vector. Proc Natl Acad Sci USA 1993. 90:10613-10617.

109. Conrad CK, Allen SS, Afione SA, Reynolds TC, Beck SE, Fee-Maki M, Barrazza-Ortiz X, Adams R, Askin FB, Carter BJ, Guggino WB, Flotte TR: Safety of single-dose administration of an adeno-associated virus (AAV)-CFTR vector in the primate lung. Gene Ther 1996, 3:658-668

1 10. Aitken ML, Moss RB, Waltz DA, Dovey ME, Tonelli MR, McNamara SC, Ginson RL, Ramsey BW, Carter BJ, Reynolds TC: A phase I study of aerosolized administration of tgAAVCF to cystic fibrosis subjects with mild lung disease. Gene Ther 200I, 12:1907-1916.

III. Moss RB, Rodman D, Spencer LT, Aitken ML, Zeitlin PL, Waltz D, Milla C, Brody AS, Clancy JP, Ramsey B, Hamblett N, Heald AE: Repeated adeno-associated virus serotype 2 aerosol-mediated cystic fibrosis transmembrane regulator gene transfer to the lungs of patients with cystic fibrosis: a multicenter, double-blind, placebo-controlled trial. Chest 2004, I 25:509-52I.

112. Snyder RO, Miao C, Meuse L, Tubb J, Donahue BA, Lin H-F, Stafford DW, Patel S, Thompson AR, Nichols T, Read MS, Bellinger DA, Brinkhous KM, Kay MA: Correction of hemophilia B in canine and murine models using recombinant adeno-associated viral vectors. Nat Med 1999, 5:64-70.

113. Herzog RW, Yang EY, Couto LB, Hagstrom JN, Elwell D, Fields PA, Burton M, Bellinger DA, Read MS, Brinhous KM, Podsakoff GM, Nichols TC, Kurtzman G], High KA: Long-term correction of canine hemophilia B by gene transfer of blood coagulation factor IX mediated by adeno-associated viral vector. Nat Med 1999, 5:56-63.

1 14. Manno CS, Chew AJ, Hutchison S, Larson PJ, Herzog RW, Arruda VR, Tal S], Ragni MV, Thompson A, Ozello M, LB Couto, Leonard DG, Johnson FA, McClelland A, Scallan C, Skarsgard E, Flake AW, Kay MA, High KA, Glader B: AAV-mediated factor IX gene transfer to skeletal muscle in patients with severe hemophilia B. Blood 2003, I 0I:2963-2972.

1 15. Arruda VR, Hagstrom JN, Deitch J, Heiman-Patterson T, Camine RM, Chu K, Fields PA, Herzog RW, Couto LB, Larson PJ, High KA: Posttranslational modifications of recombinant myotube-synthesized human factor IX. Blood 2001, 97:130-138.

1 16. High KA, Manno CS, Sabatino DE, Hutchison S, Dake M, Razavi M, et al.: Immune responses to AAV and to factor $I X$ in a phase $I$ study of AAV-mediated, liver-directed gene transfer for hemophilia B [abstract]. Mol Ther 2004, 5:s 1002.

I 17. Wang L, Calcedo R, Nichols TC, Bellinger DA, Dillow A, Verma IM, Wilson JM: Sustained correction of disease in naïve and AAV2 pretreated hemophilia B dogs: AAV2/8-mediated, liverdirected gene therapy. Blood 2005, 105:3079-3086.
118. Gao GP, Alvira MR, Wang L, Calcedo R, Johnston J, Wilson JM: Novel adeno-associated viruses fom rhesus monkeys as vectors for human gene therapy. Proc Natl Acad Sci USA 2002, 99: I |854-I I859.

119. Ryan JH, Zolotukhin S, Muzyczka N: Sequence requirements for binding of Rep68 to the adeno-associated terminal repeats. J Virol 1996, 70:1542-1553.

120. Snyder RO, Im DS, Ni T, Xiao X, Samulski RJ, Muzyczka N: Features of the adeno-associated virus origin involved in substrate recognition by the viral Rep protein. J Virol I993, 67:6096-6I04.

121. Brister JR, Muzyczka N: Mechanism of Rep-mediated adenoassociated virus origin nicking. J Virol 2000, 74:7762-777I.
Publish with Biomed Central and every scientist can read your work free of charge

"BioMed Central will be the most significant development for disseminating the results of biomedical research in our lifetime. "

Sir Paul Nurse, Cancer Research UK

Your research papers will be:

- available free of charge to the entire biomedical community

- peer reviewed and published immediately upon acceptance

- cited in PubMed and archived on PubMed Central

- yours - you keep the copyright 